\title{
Prominence, Accent and Information Structure
}

\author{
Roland Hinterhölzl (Venezia)
}

\begin{abstract}
The paper discusses the tenets of the complex interaction between syntax, prosody and information structure in German. A prominence-based approach to the interface is proposed in an account that crucially extends the object of syntax from the sentence level to the discourse level. The latter move allows to reconcile formal approaches and functional approaches to grammar and solves an old problem posed by the parallel impact of information structural categories on the phonological and semantic interpretation of the clause in generative grammar.
\end{abstract}

\section{$1 \quad$ Introduction}

In intonational languages, like English, Italian and German, information structural categories (henceforth IS-categories), like topic and focus, are very often signalled exclusively by prosodic means, that is by specific tones, metrical prominence or differences in phonological phrasing. The reader here is referred to the vast empirical (corpus) studies of Cresti (2012), Cresti and Moneglia (2010), Moneglia and Raso (2014).

These phenomena thus seem to imply a direct interaction between phonological form (PF), where prosody is taken to be dealt with, and logical form (LF), where the impact of information structure on meaning is taken to be dealt with. In the generative framework, however, a direct interaction between PF and LF is excluded, leading to the importation of interface features into the syntax, which are then interpreted in both interfaces. As an example consider the feature F in Jackendoff (1972), shorthand for focus, that is assigned to a syntactic constituent A and which is interpreted as "A constitutes new information in the utterance" at LF and as "A constitutes the most prominent element in the utterance" at PF.

In the minimalist program, syntactic computation is thought to be driven by lexical features (properties) only, excluding the presence of interface features in the syntactic computation and raising major questions on how to account properly for information structural effects in the grammar.

Things may even be more complicated than this, since the differences between speech acts is not infrequently indicated by prosodic means only, as is evident from so-called declarative questions (cf. Gunlogson 2003; Krifka 2012), as illustrated in (1). (1a) uttered with a falling intonation represents an assertion, while (1b) uttered with a raising intonation, indicated by the question mark, represents a biased question. 
a. John met Mary in the park.

b. John met Mary in the park?

Moreover, the unit of syntactic and semantic analysis is the sentence (corresponding to an entity that can be evaluated with respect to its truth value) in generative syntax. Thus the semantics (LF) deals with propositions (the sentence meaning), while the utterance meaning is relegated to an extra-grammatical unit, namely the pragmatic module (in which also IS is allocated).

Cresti (2012), Cresti and Moneglia (2010), Moneglia and Raso (2014) argue on the basis of prosodic data that the basic unit of language is the utterance (since prosodic categories can only be related to utterances and not to sentences). Note in this respect that one of the pioneers of pragmatics, namely Searle (cf. Searle 1969: 3), proposed that the basic unit of communication is the utterance and not the sentence.

Incidentally, Rizzi's (1997) proposal that there is a domain in the clause dedicated to the representation of IS-categories, illustrated in (2), may solve the above problems. His proposal has changed categorically the generative approach to language, shifting the focus from pure sentence grammar to text grammar and has the potential to reconcile generative grammar with functional approaches of the type represented by Cresti and Moneglia.

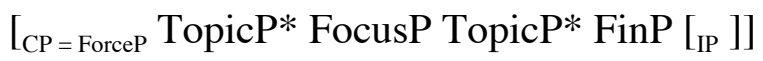

This move is complete if Rizzi's proposal is combined with work from Krifka (2014: 134) who argues for the syntactic representation of speech acts. In particular, he argues that Rizzi's ForceP hosts different speech act operators, like ASS for assertion, Q for question and so on, with the IP constituting the proposition, the former object of sentence grammar, as is illustrated in (3).

$$
\begin{aligned}
& \text { a. [ForceP } \operatorname{ASS}[\text { IP } \phi \text { (proposition)]] } \\
& \text { b. [ [ForceP } \mathrm{Q}[\mathrm{IP}\{\varphi\}] \text { ] (with the presence of } \mathrm{Q} \text { indicated by an intonational morpheme) }
\end{aligned}
$$

The paper discusses and investigates the complex interaction between syntax, prosody and IS in the so enriched minimalist program and is organized in the following way. Section 2 introduces necessary background information about the interaction between syntax and prosody. Section 3 discusses the most important notions and basic tenets of a prominence-based mapping between syntactic and prosodic structure that relies on the central concept of a phase. Section 4 addresses the issue of the complex interaction between prosodic structure and information structure in German. Section 5 discusses how IS-categories in German are made visible in the interfaces to PF and LF. Section 6 discusses implications of the present account for the general architecture of grammar and concludes the paper.

\section{Background: The interaction between syntax and prosody}

The prosodic representation of a sentence in most formal accounts distinguishes two levels of prominence above word stress, as is illustrated in (4).

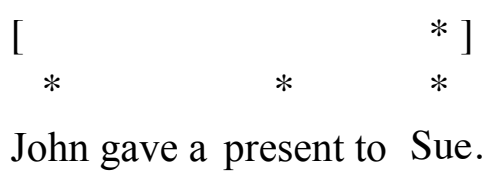


The lower level represents phrasal stress, called accent in Gussenhoven $(1983,1992)$ and Selkirk (1984, 2004). In the conception of Pierrehumbert (1980), phrasal stress combines two elements: abstract prominence and a pitch accent, typically a high tone $\left(\mathrm{H}^{*}\right)$ that is assigned to the most prominent syllable within the phrase.

Prominence at the lower level is indicated by a grid mark in the prosodic structure. It is assigned relative to the syntactic structure (see Section 3) and it entails the assignment of an obligatory pitch accent. This level of prosodic structure is identified with the level of the phonological phrase in the prosodic hierarchy of Selkirk (1984: 281), as illustrated in (5) (cf. Nespor/Vogel 1986; Selkirk 2004).

syllable $<$ foot $<$ prosodic word $<$ phonological phrase $<$ intonation phrase

Hence, the higher level in (4) is that of the intonation phrase, which in most cases corresponds to the sentence. The strongest stress of the intonation phrase, indicated by a second grid mark in (4), is usually referred to as sentence stress or nuclear stress (cf. Chomsky/Halle 1968: 17). In the following, I will refer to the nuclear stress with the terms sentence stress and main stress interchangeably.

The position of the sentence stress in many accounts is fixed by a rule that strengthens the right-most accent, as given in (6) adopted from Truckenbrodt (2013: 133).

(6) NSR: Strengthen the rightmost phrasal stress in the intonation phrase

\subsection{Focus and Accent}

Because of the special role of accents for the focus-background articulation in intonational languages, most researchers favour an accent-first based approach to the mapping between syntactic and prosodic structure (cf. Gussenhoven 1983; Uhmann 1991; Selkirk 2004).

For concreteness sake, we take a closer look at Selkirk (2004). There, she claims that the distribution of intonation pitch accents in the English sentence directly constrains the focus structure and the focus structure in turn constrains the range of meanings for the sentences. Hence, it is the tonal representation, not the phrasal stress pattern that plays a pivotal role in the meaning-prosody relation, as is illustrated in (7) and (8) below. In the following examples, sentence stress is indicated by capital letters and phrasal stress is indicated by underlining.

Note that in congruent answers to wh-questions the constituent that corresponds to the whphrase must be focused, that is, carry or contain the main accent of the sentence. It is a standard assumption since Jackendoff (1972) that the relation between pitch accent and focus is mediated by F-marking of syntactic constituents. For instance, the question in (7a) determines that the subject in the answer (7b) furnishes new relevant information, while the rest of the clause that someone will be prosecuted constitutes given information and is said to constitute the background of the answer in (7a). On the other hand, the question in (8a) determines that the predicate in the answer (8b) provides the relevant new information, with the rest of clause constituting background information.
a. Who will be prosecuted?
b. [TRESpassers $]_{\mathrm{F}}$ will be prosecuted 
a. What will be done to trespassers?

b. trespassers will be $[\text { PROsecuted }]_{\mathrm{F}}$

Since often a certain pitch accent is compatible with various focus structures, modelled as different constituents being F-marked in the approach by Jackendoff and adopted by Selkirk, focus projection rules relate pitch accents (words) and F-marking (words or phrases), as is illustrated in (9). While in (9e) the pitch accent is compatible with only one choice of focus constituent, the pitch accent in $(9 \mathrm{a}-\mathrm{d})$ is compatible with different choices of focus constituents: the NP contained in the PP, the direct object, the VP or the entire clause (example taken from Selkirk 2004).

a. Mary bought a book about $[\mathrm{BATS}]_{\mathrm{F}}$

what did Mary buy a book about? NP

b. Mary bought [a book about BATS $]_{\mathrm{F}}$ what did Mary buy?

$\mathrm{OB}$

c. Mary [bought a book about BATS $]_{\mathrm{F}}$

what did Mary do?

VP

d. [Mary bought a book about BATS $]_{\mathrm{F}}$

what happened?

IP

e. $[\mathrm{MARY}]_{\mathrm{F}}$ bought a book about bats

who bought a book about bats?

SU

To summarize, the core of accent-based accounts consists in focus projection rules which serve to derive the focus domain for a given accented constituent or vice versa, to derive the placement of the sentence accent (nuclear accent) for a given focus domain. These accounts face one major draw back. The metrical structure, which is generally taken to underlie word stress, needs to be adjusted post-hoc. For instance, in Uhmann (1991: 229), it is assumed that accented syllables are metrically reinforced by receiving an extra beat after accent assignment.

\subsection{Accent and Givenness}

Büring (2001: 2-4) proposes that focus projection rules can be dispensed with in a system in which (metrical) prominence relations are taken into account. He also argues that such a prominence-based system (also called stress-first based accounts), in addition, captures the default prosody in pre-focal structures and in clauses constituting only background information.

First, he argues that the focus projection rules proposed by Selkirk (2004) are insufficient. To see this, let us discuss the application of the focus projection rules in (10).

(10) Basic Focus Rule:

An accented word is F-marked

Focus Projection:

a. F-marking of the head of a phrase XP licenses F-marking of XP

b. F-marking of an internal argument of $\mathrm{X}$ licenses F-marking of $\mathrm{X}$

In particular, we note that the theory predicts that Focus projection is possible from complements (and heads) but not from adjuncts and specifiers. Büring (2001: 5-7) then provides examples that show that focus projection is also possible from adjuncts and subjects of a certain XP, provided that the rest within XP constitutes given information in the context. For instance, the question in (11) fixes the focus domain to the object of Bill's driving, as is also evident by the alternative answer in (11b). In the object phrase in (11a) stress falls on the ad- 
junct blue, since the fact that someone drove Mary's convertible is given information in the context of the question. Similar considerations apply to the case in (12) which displays a case of focus projection from a specifier, that is, the subject of the clause. This is so since the fact that someone bought bananas is given by the context of the question.

(11) I know that John drove Mary's red convertible. But what did Bill drive?

a. He drove $[\text { her BLUE convertible }]_{F}$

b. He drove [his MOTORCYCLE $]_{\mathrm{F}}$

(Büring 2001: 6)

(12) Why did Helena buy bananas?

a. [because JOHN bought bananas $]_{F}$

b. [because she was HUNGRY $]_{\mathrm{F}}$

(Büring 2001: 7)

Furthermore, it has been observed that the verb that is adjacent to its argument may be unstressed even if part of a wide focus on the $\mathrm{vP}^{1}$ (cf. Gussenhoven 1992: 84). This is captured by Rule (10b) in Selkirk's (2004) system and illustrated in (13a). But the same stress pattern appears if the entire vP or clause is given information, as is illustrated in (13b).

(13) a. What did the lawyer do?

He [sent the request to sell my house to their OFFICE $]_{F}$

b. Where did the lawyer you hired send the request to sell your house to?

A lawyer I know sent the request to sell my house [to their OFFICE] $]_{\mathrm{F}}$

Thus, Büring (2001) argues that these accentuation patterns should be captured not by a theory of focus projection, but by a theory of default prominence that is independent of focus. This argument is supported by the observation that the type of accent that is assigned to a phonological phrase depends on its metrical structure, as is reported in Nespor et al. (2008). In iambic phrases the accent is realized with greater duration (and intensity), while in trochaic phrases the accent is realized with greater pitch (height) (and intensity). This is a secure indication that stress is on the base of accent and not the other way round. In conclusion, a stressfirst based approach (cf. Halle/Vergnaud 1987; Ladd 1994) is to be preferred.

\subsection{Information structure: its core notions and main effects in German}

Before we go ahead it seems necessary to clarify the most important notions of IS and their role in German grammar. The IS notion that is most widely used and that was already alluded to in the previous section is the notion discourse status, distinguishing between given and new discourse referents. However, discourse status cannot be directly identified with the notions focus and background. Interlocutors make assumptions about shared information (also called common ground) in the conversation and tailor their utterances according to what they believe is already known to the hearer (background), and to what provides new relevant information (presentational focus). While new discourse referents are usually part of the focus domain, and given discourse referents are typically part of the background of the clause, this is not necessarily the case, as (14) and (15) show.

\footnotetext{
${ }^{1}$ The term vP is used for a verb phrase that introduces an external argument (an agent) in modern theory. For our purposes the differences between vPs and VPs are unimportant. I will use the term vP here since in most cases it is equivalent to the traditional term VP.
} 
(14) a. Hans hat Maria geschlagen

John has Mary beaten

b. Nein, SIE hat IHN geschlagen

No, she has him beaten

(15) a. Ich weiß nicht mehr ob Hans ein Haus oder ein Boot gekauft hat

I know not more whether John a house or a boat bought has

b. Er hat ein HAUS gekauft

He has a house bought

Focus generally indicates the presence of alternatives (cf. Krifka 2008: 247). With contrastive focus as in (14) a speaker indicates the relevance of an alternative in contradistinction to another alternative already under discussion: though the pronouns she and him are discoursegiven, they do not belong to the background of the utterance, since they are contrastively focused. In a similar vein, the direct object $a$ house in (15), though discourse-given, represents the (selective) focus of the clause. Thus, while new discourse status implies that the constituent is part of the presentational focus of the clause, given discourse status does not guarantee that it is part of the background.

It is generally assumed that given/back-grounded constituents are unstressed in German. But Uhmann (1991: 230-232) shows in an empirical study that given/back-grounded constituents preceding the focus may be accented. Their accent, however, is always less prominent than the focus accent in the clause. Only constituents representing given/back-grounded information that follows the focused constituent in the clause are obligatorily unstressed.

Furthermore, it will become important for the present approach that sentence stress (or nuclear accent) in intonational languages typically occupies a peripheral position in the intonation phrase. This feature seems to be subject to parametric variation. While sentence stress is argued to be left-peripheral in Hungarian, with preceding topics being mapped into a separate intonation phrase, sentence stress in German is right-peripheral in that domain. Thus, I propose the following restriction on the prosodic structure in German.

(16) Head Peripherality Principle:

The phonological phrase containing the sentence stress must be right-peripheral within the intonation phrase

\subsection{Basic observations about prosodic domain formation}

There are two basic approaches to deriving prosodic structure from syntactic structure. Endbased approaches (cf. Selkirk 1984) match boundaries of syntactic constituents with prosodic boundaries. These alignment rules are best expressed in an OT-like account (cf. Truckenbrodt 1999).

A simplified OT-system that derives the effects of default prominence as well as the effects of the impact of focus is given in (17) and (18) (cf. Truckenbrodt 1995, 1999; Büring 2001: 18, 2006). 
(17) $\mathrm{ADJ}=\mathrm{AD}>>*$ Stress $\mathrm{PRED}>\mathrm{XP}=\mathrm{AD}$

a. $\mathrm{ADJ}=\mathrm{AD}$ : adjuncts form accent domains

b. *Stress PRED: heads don't bear prominence

c. $\mathrm{XP}=\mathrm{AD}$ : XPs form accent domains

(18) Focus Prominence (FP) (Truckenbrodt 1995: 165)

Focus needs to be maximally prominent

Three levels of prosodic structure are assumed in this approach: the prosodic word, the accent domain $(\mathrm{AD})$ and the intonation phrase. Each prosodic unit has a head that defines the most prominent element in its domain (indicated by the asterisk on the relevant line in the grid representation). The head of the intonation phrase is the rightmost accent domain in it. Heads of accent domains carry pitch accents, nothing else does.

Q: What's new?

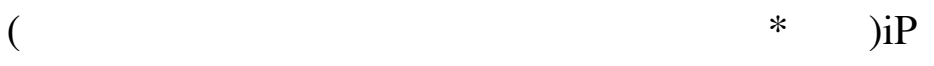

(*)AD ( * $\quad$ ( $)$ AD

A: ( John )PWd ( sold )PWd ( his house )PWd

(20) Q: What did John do with your house?

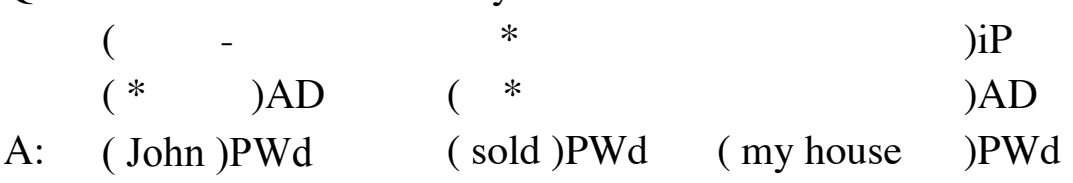

The constraints in (17) determine that (19) containing three prosodic words displays two accent domains, the second of which is assigned main prominence. Since the whole sentence in (19) constitutes new information, the constraint of focus prominence (18) does not enter the game. This is crucially different in (20) where the verb alone constitutes the focus domain of the clause. In this case, main prominence must be assigned to the verb, violating the constraint *Stress PRED in (17b). As a consequence, Focus prominence (FP) must be ranked higher than all the constraints in (17) above, to allow information structure to override the default prosodic structure dedicated by syntactic structure. We will come back to this important point in Section 4 below.

In relation-based approaches (cf. Nespor/Vogel 1986; Wagner 2005), on the other hand, prosodic constituents are built around lexical heads on the basis of the relations they entertain with adjacent constituents. The two approaches differ in the assumption of how much syntactic information is available in the interface. While end-based approaches only assume the visibility of syntactic boundaries, relation-based approaches assume the visibility of syntactic relations expressed in the $\mathrm{X}^{\prime}$-Schema.

Note in particular that prosody must have access to syntactic structure (cf. Gussenhoven 1983; Krifka 1984), since in German and Dutch arguments are phrased with the adjacent verb, while an adjunct and an adjacent verb form two separate phonological phrases, as is illustrated in (21). 
a. [ (weil Hans) (im ZELT blieb) ] since John in the tent remained

b. [ (weil Hans) (im Zelt) (RAUCHTE) ] since John in the tent smoked

Truckenbrodt (1999) in an end-based approach accounts for this difference with his WRAPrule, by assuming that objects remain in the vP and are thus properly contained in it, while adverbials being adjoined to $\mathrm{vP}$ are not properly contained by the vP and are thus phrased separately from it. Selkirk/Kratzer (2006) propose a phase-based account of the mapping between syntactic structure and prosodic structure. But both accounts are not compatible, next to Cinque's (1993) account, with the observation that arguments are licensed outside of the vdomain in German, as is illustrated in (22). Manner adverbs, which are standardly assumed to be adjoined to $\mathrm{vP}$, indicate that direct objects, even indefinite ones, are (case-)licensed in a position outside of the vP (cf. Brugger/Poletto 1995; Haiden 1995; Hinterhölzl 2006). The example in (22) is taken from Hinterhölzl (2006: 92).

(22) a. Hans hat einen Brief sorgfältig geschrieben (pure manner reading)

b. Hans hat sorgfältig einen Brief geschrieben (?? or subject related reading) John has (a letter) carefully (a letter) written

c. Hans hat einen Paragraphen genau studiert (pure manner reading)

d. Hans hat genau einen Paragraphen studiert (?? or quantificational reading) John has (a paragraph) exactly (a paragraph) studied $\left[{ }^{\mathrm{ok}}\right.$ sorgfältig $\left[{ }_{\mathrm{vP}}\right.$ Subject $\mathrm{v}_{\mathrm{c}}\left[{ }^{\mathrm{ok}} \operatorname{sorgfältig}\left[{ }_{\mathrm{vP}}\right.\right.$ Object $\left.\left.\left.\left.\mathrm{v}_{\mathrm{p}}[* \operatorname{sorgfältig}[\sqrt{\mathrm{P}}]]\right]\right]\right]\right]$

One may propose that manner adverbs occupy a vP-internal position in an analysis that decomposes the verb schreiben in (22a) in a causative vc that introduces the agent which is taken to initiate and control the process which the object undergoes in being written, represented by vp, and the verbal root which signifies the resultant state of this process, in the case of (22a) the state of the letter being completed. In this analysis, it would make sense to assume that the manner adverb can modify the causative part of the event, the process part of the event, but not the resultant state, as is illustrated in (23) above. Thus, even under a modified analysis of manner adverbs, the object in (23) must be taken to undergo movement to a higher position, outside of vcP, in order to precede the manner adverb. We will come back to this point in Section 3.2 below.

Lately, Wagner (2005) has revived the relation-based approach, initially advocated for by Nespor/Vogel (1986) in an important work on prosodic phrasing in Italian and French. He proposes that there are two modes of prosodic composition that take into account whether an argument or an adjunct follows or precedes its selecting/modified head.

In particular, he notes that while the verb and the object always form a joint phonological phrase in German, they only optionally do so in English, as is illustrated in (24).
a. [ (weil Hans) (das Buch las) ]
since Hans the book read
b. [ (since John) (read the book)]
c. [ (since John) (read) (the book) ] 
To summarize, a satisfactory account of prosodic domain formation in German must explain how the direct object, leaving the $\mathrm{vP}$, as we have seen above, gets main stress even if it is not the most deeply embedded constituent and derive the fact that object and verb always form a joint prosodic constituent in German.

\section{On the mapping between syntactic structure and prosodic structure}

Having taken note of the basic facts and central issues in the complex interaction between syntax, prosody and information structure, we will outline the basic tenets of a prominence based interface between syntactic structure and prosodic structure in the minimalist program in which the concept of phases plays an important role both in syntactic computation and in the interaction between syntax and its interfaces.

\subsection{Syntactic structure and default prominence}

If we want to follow Büring (2001) in assuming that focus projection rules can be dispensed with in a prominence based system, we need to address the basic question of where default prominence comes from. The surprisingly unspectacular answer to this question is that a simple metrical evaluation of a binary branching syntactic tree, where the right branch is interpreted as metrically strong $(s)$, yields the correct default prominence pattern of an English sentence, as is illustrated in (25).

(25) Yesterday John visited his mother

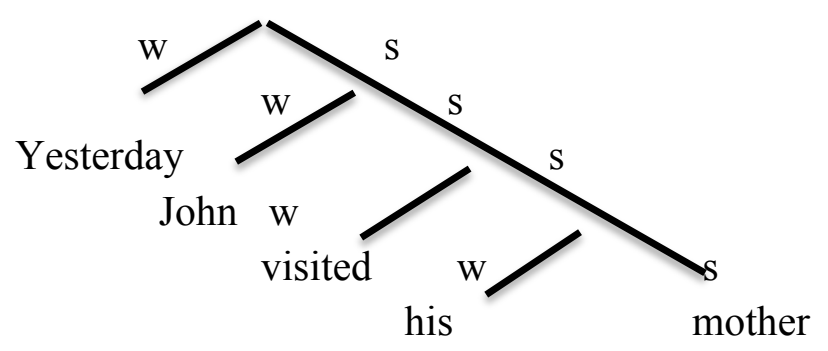

(25), in fact, records one of the oldest proposals for the derivation of sentence prosody, the bracketed metrical grid of Halle/Vergnaud (1987) in which boundaries of syntactic constituents composed of 2 or more stressed words are interpreted as metrical boundaries (only main word stresses are visible for the computation of phrasal stress) and in which the heads of line $\mathrm{N}$ constituents are located on line $\mathrm{N}+1$ with an asterisk, as is illustrated in (26) for the simple sentence John has read a book.

$\begin{array}{llllll}- & - & - & * & & \text { line 6 } \\ (- & - & - & * & ) & \text { line 5 } \\ - & (- & - & * & ) & \text { line } 4 \\ * & * & (* & * & ) & \text { line } 3\end{array}$

[John [has [ read [ a book ]]]]

Hence, I will outline an account of the mapping between syntactic structure and prosodic structure that combines a metrical evaluation of the type of Halle/Vergnaud with an explicit system of phase-based rules of prosodic domain formation following the bracketing of syntactic structure. 


\subsection{Phase-based rules of prosodic domain formation}

Phases constitute the core notion within the minimalist program. Phases are relevant for syntactic computation and are taken to constrain movement, since only constituents occupying the phase-edge, that is, the specifier of a phase-head, are taken to be able to undergo movement into the next higher phase. Phases, however, are also important for defining the interaction between the syntax and the interfaces in that they mark the points at which syntactic material is shipped to the interfaces PF and LF.

It thus will come as no surprise that the notion of a phase is defined in terms of interface properties, most importantly by LF-properties. In particular, Chomsky (2001: 35-37) proposes that the $\mathrm{vP}$ constitutes a (strong) phase since it corresponds to a complete predicate. In a similar vein, the $\mathrm{CP}$ constitutes a (strong) phase since it corresponds to the proposition expressed by the sentence (in difference to the proposal made by Krifka [2012] above). For theory internal reasons that need not interest us here, the IP constitutes a (weak) phase in this system.

In Hinterhölzl (2013: 170) this basic system is slightly modified, in order to provide a phasebased interpretation of the notion of extended projections by Grimshaw (1992) in the following way:

A) Complete phases, $\mathrm{CP}$ in the verbal domain and DP in the nominal domain, consist of several sub-phases: a predicate domain corresponding to the $\mathrm{vP}$, a licensing domain in which the arguments of a predicate and its modifiers are licensed, corresponding to the IP, and a completion domain in which the proposition expressed by IP is anchored with respect to the (pragmatic) context, corresponding to the $\mathrm{C}$-domain. In this account IP and CP are sub-phases of the same phase predicate since they belong to the extended projections of the head of the predicate domain, namely the verb.

B) Adjuncts (and tense) constitute separate phases since they are projected by separate phase predicates. In a neo-Davidsonian approach, adjuncts and tense are interpreted as predicates on the event introduced by the verb, as is illustrated for the case of a locative adjunct in (27). (27b) states/asserts that there is an event which is a meeting in the past between John and Mary and that this meeting took place in the park.

(27) a. John met Mary in the park

b. $\exists$ e meeting $(\mathrm{J}, \mathrm{M}, \mathrm{e}) \&$ past (e) \& in the park (e)

In this system, adjuncts qua predicates (on the event argument) constitute separate phases with respect to the verb and its arguments, as elements contained in the sub-phases projected by the verb. Based on this notion, Hinterhölzl (2009), following Wagner (2005), proposes two modes of prosodic composition that take into account the phase status of two adjacent syntactic constituents, as defined in (28).

(28) Modes of prosodic composition (Hinterhölzl 2013: 174)

a. subordination: (DP) $+\mathrm{V} \rightarrow((\mathrm{DP}) \mathrm{V})$

b. coordination: $(\mathrm{PP}) \& \mathrm{~V} \rightarrow(\mathrm{PP})(\mathrm{V})$

Subordination pertains to constituents that belong to the same phase-predicate (a predicate and its arguments) and maps them onto a joint prosodic constituent, namely onto a phonologi- 
cal phrase, while coordination pertains to constituents that belong to different phasepredicates (the verb and event-related adjuncts) and maps them onto two separate phonological phrases.

Prosodic constituents need to be headed. I propose the relevance of two types of heading procedures, defined in (29): Extrinsic heading refers to the position of a constituent in the syntactic tree, while intrinsic heading makes reference to the prosodic properties of two constituents to be combined within a prosodic constituent. For instance, intrinsic heading is relevant for the combination of a clitic with its host, normally constituted by a prosodic word, in which the syllable representing the clitic counts as inherently weak independent of its position, that is to say, independently of whether it is proclitic or enclitic in nature.

a. Extrinsic heading:

In prosodic composition, the right-hand member is metrically stronger than its sister constituent

\section{b. Intrinsic heading:}

In the combination of two distinct prosodic constituents, the constituent that is higher on the hierarchical layer counts as metrically stronger than its sister constituent

Intrinsic heading also accounts for the metrical properties of objects in German, which precede the verb and are not the most deeply embedded constituents in the clause (cf. Cinque 1993). In particular, intrinsic heading makes use of phase-theory: when the combination of a verb and its complement is evaluated prosodically, there is an intrinsic asymmetry: the DPargument constituting a complete phase has already been mapped onto a phonological phrase when combined with the verb, which is standardly mapped onto a prosodic word.

If we assume, along the lines of Halle/Vergnaud (1987), that during prosodic evaluation the labelled tree is converted into a bracketed grid representation, the relative strengths of the several accents in the clause are derived, as is illustrated in (30) for a putative German sentence comprising a subject DP, two adjunct XPs and a direct object DP and the verb.

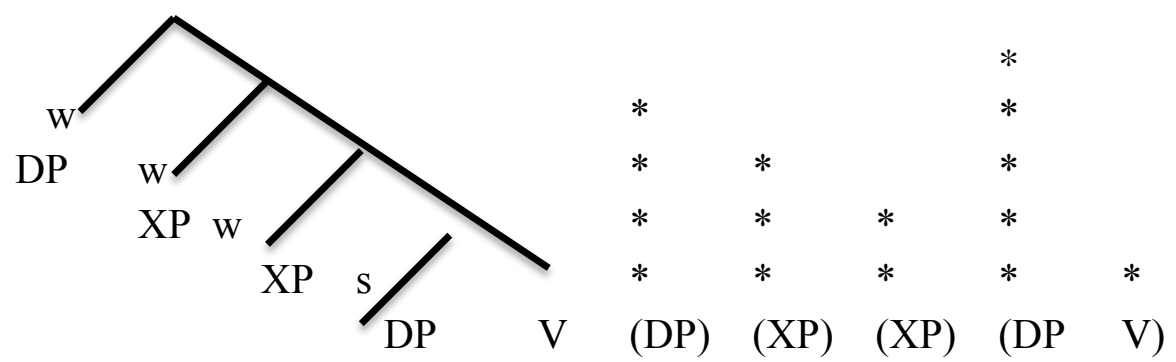

The operation of subordination creates recursive prosodic structures that violate the strict layer hypothesis (Selkirk 1984, Nespor/Vogel 1986: 8). However, Ladd (1986), Selkirk (2004), Peperkamp (1997) and Truckenbrodt (1999) provide arguments for the availability of recursive prosodic structures in certain languages.

Here, I propose that the syntax derives an initial recursive prosodic phrasing which at a later level may be flattened by language specific rules that delete outer boundaries in a cyclic fashion according to global prosodic parameters like rhythm, length and branchingness of constituents and the like. Furthermore, I follow Nespor/Vogel (1986: 172-174), who propose the 
operation of restructuring to account for a flexible prosodic phrasing in Italian and French, as is illustrated in (31). In Italian verb and object are phrased into separate phonological phrases, unless the object is non-branching. In this case the object may restructure with the verb, that is, become a part of the phonological phrase projected by the verb.
a. (Gianni) (ha mangiato) (una mela)
b. (Gianni) (ha mangiato mele)

To account for this effect, I will assume the following definition of restructuring in (32) and a corollary pertaining to non-branching constituents, as is illustrated in (33).
a. restructuring:
an un-phrased prosodic constituent restructures with an adjacent prosodic constituent crossing maximally one prosodic boundary
b. corollary: non-branching prosodic constituents delete redundant prosodic

$(\phi(\operatorname{pwd} N)) \rightarrow(\operatorname{pwd} N)$

Let us see how the system works in detail, discussing the case of the mapping of a simple German sentence onto PF. After the initial prosodic phrasing is derived in the interface, the obtained structure is simplified by the way of the deletion of outer boundaries and restructuring operations. The latter step is constrained by the principle in (34) which records the various faithfulness constraints of segmental phonology.

\section{Preservation of main prominence:}

The deletion of prosodic boundaries must not alter pre-established prominence relations

For reasons of simplicity, we assume in (35) that the subject constitutes a topic and is phrased separately from the verbal predicate, forming a phonological phrase with the conjunction. (35b) displays the initial prosodic phrasing which involves a recursive phonological phrase containing the phonological phrases of both objects and the verb. This structure needs to be simplified in phonology proper by deletion and restructuring operations obeying the condition in (34). After the second step of the deletion of the respective outer boundary an un-phrased prosodic category pertaining to the phonological word of the verb is obtained. This unphrased category must be either rephrased according to the prosodic category of its prosodic sister in order to obey the SLH or undergo restructuring into the adjacent phonological phrase of the direct object.

(35) a. weil Hans der Maria ein Buch gab since Hans to-the Maria a book gave

b. (weil Hans) ((der Maria) ((ein Buch) gab)) < deletion of outer boundary

c. (weil Hans) (der Maria) ((ein Buch) gab) < deletion of outer boundary

d. (weil Hans) (der Maria) (ein Buch) gab

e. (weil Hans) (der Maria) (ein Buch gab) result of restructuring of (d)

f. (weil Hans) (der Maria) (ein Buch) (gab) rephrasing of the final pwd

Note, however, that (35f) is ungrammatical since the phrasing does not preserve main stress on the direct object. The prosodic structure in (35f) would assign main stress to the verb, since only extrinsic heading is available in this structure. The only option to avoid a recursive pro- 
sodic phrasing is thus to restructure the verb with the direct object, deriving that object and verb must obligatorily form a prosodic constituent in German. No such effect occurs in the order VO: independently of the phrasing, the main stress remains on the object, as is illustrated in (36).
a. (John) (read (a book))
$<$ deletion of outer boundary
b. (John) read (a book)
c. (John) (read a book)
restructuring
d. (John) (read) (a book)
rephrasing

To summarize, the principle in (34) ensures that rephrasing is not an option in the order OV, but is optional in the order VO. It is thus to be expected that special metrical conditions apply to these options in VO languages, as has been illustrated for Italian above. The latter can be characterized as a language that excludes restructuring of the verb with the object if the object is branching. Taken together, the facts of prosodic domain formation in German, English and Italian provide strong support for the initial recursive prosodic phrasing derived from syntactic structure as advocated above.

\section{$4 \quad$ Prosodic structure and IS}

As we have discussed in section 2 above, prosodic structure is not only determined by and derived from syntactic structure, as illustrated in (30) and (35) above, but it is also crucially determined by information structure (IS). In particular, it must be assured that the focused constituent in an utterance is assigned the main stress independently of its position in the clause. This is the reason why Jackendoff (1972) argued for the introduction of a syntactic feature $\mathrm{F}$ (for focus) that is interpreted both at PF and LF, with the PF-interpretation given as in (37) below. A similar constraint, called Focus Prominence, as we have seen above is also proposed in Truckenbrodt (1995), repeated here in (38).

(37) Prosodic Effect of F (Jackendoff 1972)

$\mathrm{F}$ attracts the strongest stress of the sentence

(38) Focus Prominence (Truckenbrodt 1995: 165)

Focus needs to be maximally prominent

In a prominence-based approach, in which the relative strength of an accent depends on its metrical value in the clause, this implies that there exists a mapping relation between metrical constituents and IS-categories. Since it is observed that given elements in the languages under discussion are typically prosodically weak and often de-stressed, accent-first based systems assume a special interface condition for constituents representing background information, usually marked with the feature $\mathrm{G}$ (for given information), as is illustrated in (39). In the present account, (39) can be remodelled by the condition in (40).

(39) Prosodic effect of G (Féry/Samek-Lodovici 2006):

$\mathrm{G}$ rejects sentence and phrasal stress

(40) G-Transparency (PF-transparency):

A given constituent must occupy a weak position in prosodic structure 
There are basically two ways of satisfying the condition in (40). A) A given argument moves out of its post-verbal (strong) base position and is spelled-out in a preverbal position, which necessarily counts as metrically weak. This derives the strong tendency in languages to realize given elements to the left of the verb. B) The default value assigned in prosodic composition to a given post-verbal constituent is overridden by projecting its intrinsic prosodic value, namely weak $(\mathrm{w})$, in prosodic composition. We have a case of de-accenting in situ, which in the present system represents the second case of sensitivity to inherent metrical properties in prosodic domain formation, as is illustrated in (41) and defined in (42) below.

The empirical result of this option is that stress and main accent will shift locally to the lefthand prosodic sister of a given constituent, as illustrated in (41). In (41), main stress falls on the verb, as is indicated by underlining. The respective prosodic constituents have the metrical values given in (41B). In (41), the verb is assigned the metrical value strong, since its prosodic sister is projecting its intrinsic value weak according to its discourse-given status.

(41) A: Did Peter visit his sister?

B: No, John wrote to his sister

$\left((\text { John })^{\mathrm{w}}{ }^{\mathrm{s}}\left({ }^{\mathrm{s}}\right.\right.$ wrote $^{\mathrm{w}}$ ( to his sister $\left.\left.)\right)\right)$

(42) Weakness-sensitivity:

A given constituent projects its inherent metrical value weak (w) independently of its metrical position in the structure

Parallel to the condition in (40), I assume an interface condition for elements representing new information, as given in (41).

F-Transparency (PF-transparency):

A constituent representing new information must occupy a strong position in prosodic structure

There are basically two ways of satisfying the condition in (43). First, a focussed constituent is spelled out in its base position in the vP. Since prosodic domain formation starts with the verb, constituents joined to the left side of (the prosodic constituent containing) the verb occupy a weak branch and constituents joined to the right of (the prosodic constituent containing) the verb occupy a strong branch, if the procedure of extrinsic heading is used exclusively in the process of prosodic domain formation. This implies that constituents representing new information focus in these languages should be realized to the right of the verb.

The second option consists in using intrinsic heading in the process of prosodic domain formation, as we have argued above is the case of German. Note, however, that in this way only one constituent representing new information can occupy a strong branch in prosodic structure. In the context of (44) both the direct object and the indirect object represent new information, but only the direct object can occupy a strong branch with respect to the verb in prosodic structure. This issue will be addressed in the following section, where it is argued that German is an LF-transparent language.
A: What did Hans do?
B: Hans hat [dem Nachbarkind ein Buch geschenkt $]_{\mathrm{F}}$ Hans has to-the neighbour's child a book given 
I want to conclude this section addressing a problem that is at the heart of deterministic prominence based approaches to the interface between syntax, prosody and information structure. This problem arises in cases of contrastive focus, which often or typically involve given constituents, as is illustrated in (45).
A: John insulted Mary
B: No, $[\mathrm{she}]_{\mathrm{CF}}$ insulted $[\mathrm{him}]_{\mathrm{CF}}$

The problem in (45B) is that the pronouns she and him constitute both given and contrastively focused information. In (45), speaker B makes a complex judgment. He accepts that there was an event of insulting co-involving John and Mary but rejects that John was the agent and Mary was the patient in the event and consequently corrects speaker A with a contrastive statement. Thus we can say that insult constitutes background information between hearer and speaker. What is problematic in (45) for the present account is that we have to assume that the pronouns are interpreted as given, since speaker B accepts the references to the individuals John and Mary. Thus, subject and object in (45B) must be taken to be endowed with the discourse feature [+ given] to obtain their correct interpretation at LF (see section 5 below). This feature, however, requires that subject and object occupy weak branches at PF, excluding the possibility that they obtain main stress in the utterances, as requested by their parallel status of contrastively focused constituents.

We have arrived at an impasse here. The account so far works perfect for sentences with wide focus, where given constituents are contained in a larger focus domain, but fails badly in sentences containing contrastively focused constituents which are given at the same time.

Note that this problem does not appear in an OT-approach to the interface, which permits constraints to be violated and selects as grammatical the candidate that does not violate the highest ranked constraint. As we have seen in section 2 above, Focus Prominence is taken to outrank any constraint, including those imposed by givenness. We have to look for another solution that also respects the general idea of this paper, namely that prominence is at the heart of the distinction between focus and background and that prominence is determined by metrical categories. We should slightly back-track at this point.

In the present system, the prominence of a prosodic constituent is determined by its syntactic position (extrinsic heading) and by its inherent metrical properties due to its information structural status (intrinsic heading). But the prominence of a prosodic constituent is ultimately decided by its head status in the metrical grid.

Along this line, I propose that in a focus-background division the focused constituent always counts as the head of the joint prosodic category. We can now envisage a reformulation of the standard heading procedure in (29) above, that takes into consideration the focus-background partition of a complex statement like (45B), illustrated in (46), where B stands for background information and $\mathrm{F}$ and $\mathrm{G}$ have the values introduced above. The correct accentuation of (46) is derived by the revised heading procedure in (47).

$$
\begin{aligned}
& \text { No, }\left[_{F}\left[{ }_{G} \text { she }\right]\right]\left[_{B} \text { insulted }\right]\left[_{F}\left[{ }_{G} \text { him }\right]\right] \\
& \text { Heading procedure (final version): }
\end{aligned}
$$


(47) In the combination of a B-marked and an F-marked prosodic constituent, the Fmarked constituent counts as the head of the resultant constituent; elsewhere the head is determined by the metrical values of the two combining constituents, that is, by extrinsic and intrinsic heading

Given (47), the pronouns in (46) may occupy weak branches in prosodic structure, respecting their discourse given status, but due to the presence of the discourse features $\mathrm{F}$ and $\mathrm{B}$, the head of the prosodic constituent comprising the B-marked verb and the F-marked object will be the direct object, as is illustrated in (48). Consequently, in the metrical grid the two pronouns will be more prominent than the verb.

(48) No, she insulted him

In the first step, combining verb and object, the object projects up onto the next line, despite the fact that it occupies a weak branch in the metrical tree. In the second step, combining subject and the predicate, where the elsewhere condition applies, head status will be assigned to the predicate, correctly deriving the fact that the object constitutes the most prominent element in (46), followed by the subject.

Head Peripherality in (16) above will require that the two foci in (48) are probably mapped into two separate intonation phrases, as is indicated in (49). I will have to leave this point for further research. In (49), square brackets stand for intonation phrases and round brackets symbolize phonological phrases.

$$
\text { [ (SHE) ] [( insulted HIM) ] }
$$

How can the effect that back-grounded constituents are de-accented after the focused constituent be obtained in the present account? I will argue that this effect is achieved by the assumption that background constituents can be optionally de-phrased. The head peripherality (HP) principle in (16) above will then ensure that the initial recursive prosodic phrasing is flattened by restructuring operations to the effect that the phonological phrase containing the focus obtains a right-peripheral position within the intonation phrase, as is illustrated in (50).

(50) A: Wem hat Hans eine Rose geschenkt?

Whom has John a rose given

B: Hans hat [seiner Mutter $]_{\mathrm{F}}$ eine Rose geschenkt

John has his mother a rose given

a. (Hans) (hat) ((seiner Mutter) $)_{\mathrm{F}}(($ eine Rose) geschenkt)) initial phrasing

b. (Hans) (hat) (seiner Mutter) ((eine Rose) geschenkt) outer boundary-deletion

c. (Hans ) (hat) (seiner Mutter) (eine Rose) geschenkt outer boundary-deletion

d. (Hans) (hat) (seiner Mutter) $)_{\mathrm{F}}$ (eine Rose geschenkt) restructuring of the verb

e. (Hans) (hat) (seiner Mutter) eine Rose geschenkt de-phrasing of B

f. (Hans) (hat) (seiner Mutter eine Rose geschenkt) restructuring of B

To conclude, with the revised heading procedure in (47), the enterprise of putting the complex relation of information structure and accentuation on a metrical basis has been completed suc- 
cessfully. We can now say that also the sentence accent like the word accent is determined by metrical properties. The effect of information structure on accentuation patterns that is often described as overriding default prominence is integrated in a rule that organically combines default prominence and focus effects within the same procedure of relating syntactic structure and information structure with standard categories of metrical phonology.

\section{$5 \quad$ LF-transparency in German}

In the previous section, we have seen that IS-categories are not PF-transparent in German. In particular, constituents representing new information are not always spelled out on a strong branch with respect to the verb.

Note, however, that IS-categories cannot only be made visible via prosodic properties but also via LF-properties like scope. We observe that German compared to English is a so-called rigid scope language. As is illustrated in (51), scope follows word order in a rigid scope language, but is independent of word order in a flexible scope language like English. While (51a) is ambiguous in the way indicated, (51b) only allows for the reading that corresponds to the surface position of the two quantified elements.
a. Some man loves every woman (ambiguous)
"some man is such that he loves every woman"
"for every woman there is a possibly different man that loves her"
b. weil ein Mann jede Frau liebt (unambiguous)
c. weil jede Frau ein Mann liebt (ambiguous)

It is generally assumed that (51a) is ambiguous because of the presence of Quantifier Raising $(\mathrm{QR})$, an operation that takes place at LF and thus remains invisible in the overt syntax. For (51b) in German, the absence of QR has to be assumed. To derive the so-called inverted reading in which the object takes scope over the subject, German makes use of overt scrambling instead (51c). (51c) is ambiguous because it is assumed that the scrambled object can reconstruct, that is, be put back into its post-subject position at LF which is the level of representation of logical meaning or sentence meaning.

If scope positions are in the I-domain, as is argued by Lechner (2010), an OV-language like German can be characterized as a scope-transparent language within an approach adopting the Universal Base Hypothesis (UBH) (cf. Kayne 1994). This approach assumes that all languages have a basic head initial or VO order. OV languages in this approach are characterized by moving and spelling out constituents of the vP in the I-domain. In such a scenario, one may assume that English and German are not so different as it seems: they both move vPinternal material into the I-domain, but in English these elements are spelled-out in the v-domain, hence post-verbally, while in German these elements are spelled-out in the Idomain. Due to PF-transparency arguments are spelled-out in the v-domain in English. For German, we can assume the principle in (52) that assures that arguments are spelled-out in the I-domain.

(52) Scope Transparency

An argument is spelled out in its (highest) scope position 
(52) elegantly explains the positioning of quantificational arguments. To account for the parallel positioning of referential arguments, I would like to make the proposal that IScategories, too, are made visible via scope-relations in German.

This idea is based on a proposal by Jacobs (1988: 95) who argues that new information focus, like other focus types, is bound by a focus operator, in his account the assertion operator (A). This can be implemented by the assumption that constituents being part of new information must enter into an Agree relation with this operator in the C-domain, as is illustrated in (53a). Due to the Phase Impenetrability Condition, which restricts the distance of Agree relations to one phase, elements representing new information must be interpreted in the I-domain at LF and hence will be spelled out in the I-domain in German. The semantic/pragmatic impact of this Agree relation is that a new discourse referent (DR) with the relevant features is added to the common ground $(\mathrm{CG})$, i. e. the shared knowledge of speaker and hearer. We will say that new information focus in German is LF-transparent, because it is realized in its LF-position.

Along these lines, I propose a similar Agree relation for given discourse referents which I assume to be bound by the $\mathrm{G}$ operator, where $\mathrm{G}$ stands for givenness, as is illustrated in (53b). This relation is interpreted as the retrieval of the most salient DR with the respective features from the CG. In (53), spelled-out copies are underlined.

$$
\begin{aligned}
& \text { a. }\left[{ } _ { \mathrm { CP } } \mathrm { A } \quad \left[{ }_{\mathrm{IP}} \underline{\mathrm{DP}}_{\mathrm{F}}\left[_{\mathrm{vP}} \mathrm{V} \quad \mathrm{DP}_{\mathrm{F}}\right]\right.\right. \\
& \text { b. }\left[{ } _ { \mathrm { CP } } \mathrm { G } \left[_{\mathrm{IP}} \underline{\mathrm{DP}}_{\mathrm{G}}\left[{ }_{\mathrm{vP}} \mathrm{V} \mathrm{DP}_{\mathrm{G}}\right]\right.\right.
\end{aligned}
$$

To conclude, let us address the question whether word order in German does not display any effect of PF-transparency. While there is no evidence that either given or new information is spelled-out in specific positions in the German I-domain, we may assume a condition like (54). This condition will ensure that given information typically precedes new information in the German middle field (when abstracting away from de-accenting in situ, which remains a marked option in German).

(54) PF-transparency (German)

Constituents representing new information occupy a stronger position in prosodic structure than constituents representing given information

\section{Implications for the general architecture of the grammar}

The account presented in this paper raises a number of issues concerning standard assumptions about the interaction between syntax, PF and LF. First, there is the issue of how and when the IS-labels F and G are introduced in the derivation. Since these features are important for the syntactic computation, for instance, G-marked constituents undergo scrambling in German, they must be introduced before syntactic structures are shipped into PF and LF, but cannot be taken to constitute lexical features.

Note, however, that in a phase-based system, we can envisage the following solution to this problem. In a phase-based system syntactic material is shipped to LF and PF at the completion of DP and CP. In particular, I propose that a complete DP-phase at this point of the derivation is evaluated both prosodically - it is mapped onto a phonological phrase - and infor- 
mation-structurally - among other things, it is assigned the labels $F$ and $G$ according to the context.

The second issue concerns the question of where the transparency conditions in (40) and (43) are taken to apply. One possibility would be that they apply in the mapping between syntactic structure and prosodic structure (PS). But this is not an elegant solution, since it would require that the IS-labels F and G are present in prosodic structure, which is implausible. The alternative is to assume that IS is not really an integral part of LF, but is part of the interface to LF in a parallel way that PS is part of the interface to PF. In this account, G-Transparency and F-Transparency can be taken to be conditions on the mapping between PS and IS, as is illustrated in (55). In (55), S-T stands for Scope-Transparency.

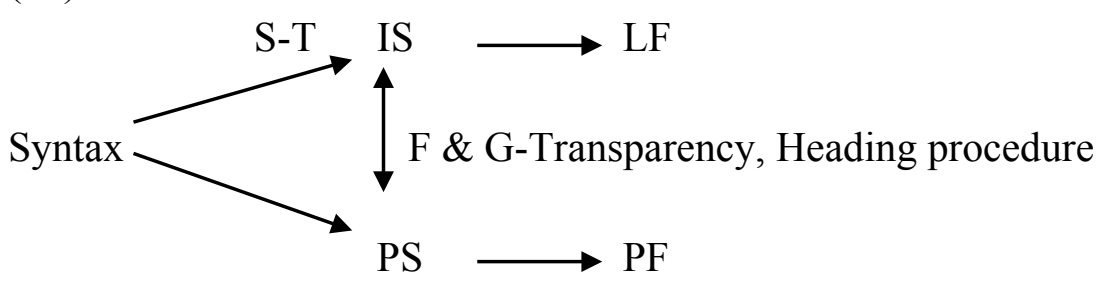

The architecture in (55) also presents a solution to the third issue posed by the present account, which concerns the question where IS-categories - F and B (for background) are introduced. Since these features are not relevant for the syntactic computation, we may assume they are introduced in IS which directly interacts with PS.

This analysis of IS as an interface level between syntax and LF is unorthodox and thus requires some further discussion. It is standardly assumed that LF represents the truthfunctional part of the meaning of a sentence, which is enriched in the semantic component or in an interface with pragmatics with contextual information to arrive at the utterance meaning. Under these assumptions, IS should apply after syntactic information has been mapped onto LF, also because pragmatic information including IS is taken to have no impact on the truthconditions of the sentence.

Note, however, that the latter assumption is wrong, since focus does clearly have an impact on the truth-value of the sentence, as has been pointed out by Szendröi (2004: 233) and is illustrated in (56). The sentences in (56a) and (56b) only differ in the placement of the main accent, but clearly have different truth conditions: while (56a) is true in a situation in which John introduced Sue and Mary to Bill and to nobody else, (56b) is false in this situation.

$$
\begin{aligned}
& \text { a. John only introduced Sue to BILL } \\
& \text { b. John only introduced SUE to Bill }
\end{aligned}
$$

Furthermore, note that in the framework that I am advocating the truth-functional part of the meaning is represented by the sub-phase of the I-domain. Remember that here we follow Krifka (2014) who assumes that the IP represents the proposition (understood as a function from contexts to truth-values) that is to be evaluated with contextual information represented in the C-domain of the clause.

Thus it is only coherent to assume that the C-domain is initiated by a speech act operator, which in turn may be taken to introduce the standardly assumed contextual values of the ut- 
terance situation (including speaker, addressee, time, location and the common ground). Evidence for this proposal comes from a number of recent publications providing good arguments that pragmatic information is represented in the syntax. See Giorgi (2010), Bianchi (2006) and Sigurdsson (2011) for arguments for the syntactic representation of the speaker, the addressee and the speech time. See Krifka (2014) for a proposal of how to represent speech acts in syntactic structure.

In conclusion, when the complete phase CP is semantically evaluated, we arrive directly at the utterance meaning, with the sub-phase IP contributing the truth-functional part of the meaning. When the CP phase is evaluated semantically, access is needed to the pragmatic component. In the present account, this access is achieved via the interface component IS. The architecture in (53) together with the assumption of a phase-based mapping of syntactic structure onto PF and LF solves the long-standing problem within the minimalist program discussed in Szendröi (2004: 247) - namely the fact that either the inclusiveness condition has to be given up or direct interaction between PF and LF has to be assumed. In the approach advocated here, neither the one nor the other assumption has to be given up.

\section{References}

Bianchi, Valentina (2006): "On the syntax of personal arguments". Lingua 116: 2023-2067.

Brugger, Gerhard/Poletto, Cecilia (1995): "On negation in German and Bavarian”. Rivista di Grammatica Generativa 20: 111-159.

Büring, Daniel (2001): Focus projection and default prominence. Ms., UCLA. http://sem anticsarchive.net/Archive/DVmMzI4M/buring.focus.projection.03.pdf [21.08.2017].

Cinque, Guglielmo (1993): “A null theory of phrase and compound stress”. Linguistic Inquiry 24: 239-297.

Chomsky, Noam (1995): "Bare phrase structure". In: Webelhuth, Gert (ed.): Government and binding theory and the minimalist program. Cambridge/MA, Blackwell: 383-439.

Chomsky, Noam (1998): Minimalist explorations. Ms. Cambridge/MA: MIT.

Chomsky, Noam (2001): "Derivation by phase". In: Kenstowicz, Michael (ed.): Ken Hale: A life in language. Cambridge/MA, MIT: 1-52.

Chomsky, Noam (2005): On phases. Ms. Cambridge/MA: MIT.

Cresti, Emanuela/Moneglia, Massimo (2010): "Informational-Patterning Theory and the corpus-based description of spoken language. The compositionality issue in the topiccomment pattern". In: Moneglia, Massimo/Panunzi, Alessandro (eds.): Bootstrapping information from corpora in a cross-linguistic perspective. Firenze, Firenze University Press: $13-45$.

Cresti, Emanuela (2012): "The definition of focus in the Language into Act Theory". In: Mello, Helliano/Panunzi, Alessandro/Raso, Tommaso (eds.): Illocution, modality, attitude, information patterning and speech annotation. Firenze, Firenze University Press: 39-83.

Fery, Caroline/Samek-Lodovici, Vieri (2006): "Focus projection and prosodic prominence in nested foci". Language 82/1: 131-150.

Frascarelli, Mara/Hinterhölzl, Roland (2007): “Types of topics in German and Italian”. In: Schwabe, Kerstin/Winkler, Susanne (eds.): On information structure, meaning and form. Amsterdam, Benjamins: 87-116. 
Giorgi, Alessandra (2010): About the speaker: Towards a syntax of indexicality. Oxford: Oxford University Press.

Grimshaw, Jane (1991): Extended projections. Ms. Brandeis University.

Gunlogson, Christine (2003): True to form: Rising and falling declaratives as questions in English. New York: Routledge.

Gussenhoven, Carlos (1983): On the grammar and semantics of sentence accents. Dordrecht: Foris.

Gussenhoven, Carlos (1992): "Sentence accents and argument structure". In: Roca, Iggy (ed.): Thematic Structure, its role in grammar. Berlin/New York, Foris: 79-106.

Haiden, Martin (1995): On the semantic evaluation of NP-syntax. Diploma Project. University of Vienna.

Haider, Hubert (1993): Deutsche Syntax, generativ: Vorstudien zur Theorie einer projektiven Grammatik. Tübingen: Narr.

Haider, Hubert (2000): “Adverb placement-convergence of structure and licensing”. Theoretical Linguistics 26: 95-134.

Halle, Morris/Vergnaud, Jean-Roger (1987): An essay on stress. Cambridge/MA: MIT.

Halle, Morris/Marantz, Alec (1993): "Distributed morphology and the pieces of inflection". In: Hale, Kenneth/Keyser, Samuel J. (eds.): The view from building 20. Cambridge/MA, MIT: 111-176.

Hinterhölzl, Roland (2006): Scrambling, remnant movement, and restructuring in West Germanic. Oxford/New York: Oxford University Press.

Hinterhölzl, Roland (2013): “(Dis)Harmonic Word Order and Phase-Based Restrictions on Phrasing and Spell-Out”. In: Biberauer, Theresa/Sheehan, Michelle (eds.): Theoretical Approaches to Disharmonic Word Order. Oxford, Oxford University Press: 162-189.

Jacobs, Joachim (1988): „Fokus-Hintergrund-Gliederung und Grammatik“. In: Altmann, Hans (ed.): Intonationsforschungen. Tübingen, Niemeyer: 89-134.

Kayne, Richard (1994): "The antisymmetry of syntax". Linguistic Inquiry Monograph 25. Cambridge/MA: MIT.

Kayne, Richard (1998): “Overt versus covert movement”. Syntax 1/2: 128-191.

Krifka, Manfred (1984): Fokus, Topik, syntaktische Struktur und semantische Interpretation. http://amor.cms.hu-berlin.de/ h2816i3x/Publications/Krifka\%201984\%20Fokus.PDF [08.05.2017].

Krifka, Manfred (2008): “Basic notions of information structure”. Acta Linguistica Hungarica 55: 243-276.

Krifka, Manfred (2014): "Embedding illocutionary acts”. In: Roeper, Tom/Speas, Margret (eds.): Recursion, Complexity in Cognition. Berlin, Springer: 125-155.

Krifka, Manfred (2017): “Negated polarity questions as denegations of assertions”. In: Kiefer, Ferenc/Lee, Chungmin/Krifka, Manfred (eds.): Contrastiveness and scalar implicatures. Berlin, Springer: 359-398.

Ladd, Robert Dwight (1986): "Intonational phrasing: The case for recursive prosodic structure". Phonology 3: 311-340.

Lechner, Winfried (2010): “Two kinds of reconstruction”. Studia Linguistica 52/3: 276-310.

Lieberman, Mark/Prince, Alan (1977): "On stress and linguistic rhythm". Linguistic Inquiry 8: 249-336. 
Moneglia, Massimo/Raso, Tommaso (2014): "Notes on Language into Act Theory”. In: Raso, Tommaso/Mello, Heliana (eds.): Spoken corpora and linguistics studies. Amsterdam/NewYork, Benjamins: 468-489.

Nespor, Marina/Vogel, Irene (1986): Prosodic phonology. Dordrecht: Foris.

Nespor, Marina et al. (2008): "Different phrasal prominence relations in VO and OV languages". Lingue e Linguaggio VII/2: 1-29.

Peperkamp, Sharon (1997): Prosodic Words. The Hague: Holland Academic Graphics. (= HIL dissertations 34).

Selkirk, Elisabeth (1984): Phonology and syntax: The Relation between sound and structure. Cambridge/MA: MIT.

Selkirk, Elisabeth (2004): "The prosodic structure of function words". In: McCarthy, John (ed.): Optimality theory in phonology: a reader. Oxford, Blackwell: 464-482.

Sigurdsson, Halldór Ármann (2011): "Conditions on argument drop". Linguistic Inquiry 42/2: 267-304.

Szendröi, Kriszta (2004): "Focus and the interaction between syntax and pragmatics". Lingua 114: 229-254.

Truckenbrodt, Hubert (1999): “On the relation between syntactic phrases and phonological phrases”. Linguistic Inquiry 30: 219-255.

Truckenbrodt, Hubert (2013): “An analysis of prosodic F-effects in interrogatives: Prosody, syntax and semantics". Lingua 124: 131-175.

Uhmann, Susanne (1991): Fokusphonologie. Tübingen: Niemeyer.

Wagner, Michael (2005): “Asymmetries in prosodic domain formation”. In: Richards, Norvin/Mcginnis, Martha (eds.): Perspectives on Phases. Cambridge/MA, MIT: 329-367. (= MITWPL 49). 